\title{
Absorption Characteristics of Lightweight Concrete Containing Densified Polystyrene
}

\author{
Bengin M. A. Herki ${ }^{a^{*}}$ \\ ${ }^{a}$ Faculty of Engineering, Soran University, Soran, Erbil, Kurdistan Region-Iraq.
}

Received 29 July 2017; Accepted 28 August 2017

\begin{abstract}
The environmental impacts of the construction industry can be minimised through using waste and recycled materials to replace natural resources. Results are presented of an experimental study concerning capillary transport of water in concrete incorporating densified expanded polystyrene (EPS) as a novel aggregate. A new environmentally friendly technique of densifying was used to improve the resistance to segregation of EPS beads in concrete. Twelve concrete mixes with three different water/cement ratios of $0.6,0.8$ and 1.0 with varying novel aggregate content ratios of $0,30,60$ and $100 \%$ as partial replacement for natural aggregate by equivalent volume were prepared and tested. Total absorption, absorption by capillary action, and compressive strength was determined for the various concrete mixes at different curing times. The results indicated that there is an increase in total water absorption (WA) and capillary water absorption (CWA) and a decrease in compressive strength with increasing amounts of the novel aggregate in concrete. However, there is no significant difference between the CWA of control and concretes containing lower replacement level.
\end{abstract}

Keywords: Capillary Water Absorption; Compressive Strength; Concrete; Environment; Recycling; Waste Expanded Polystyrene.

\section{Introduction}

The environmental impacts of the construction industry have been a major contributor to the environment pollution all over the world. However, these impacts can be minimized through using waste and recycled materials e.g. waste polystyrene to replace natural resources. Many by-products and solid recyclable materials can be used in concrete mixtures as aggregates or cement replacement, depending on their chemical and physical characterization; thus concrete can become an environmentally sustainable material [1].

According to the literature, capillary water absorption (CWA) of concrete is the phenomenon by which water is absorbed into concrete by capillary action [2,3]. Generally, to examine the durability of concrete, absorption characteristics including CWA is employed. A recent study [4] investigated the effect of EPS aggregate size on strength and moisture migration characteristics of lightweight concrete containing fly ash as a supplementary cementitious material. The results indicate that for comparable aggregate size and concrete density, concrete with unexpanded polystyrene (UEPS) aggregate exhibited 70\% higher compressive strength than EPS aggregate. Moreover, the results indicate that the EPS concrete containing bigger size and higher volumes of EPS beads show higher moisture migration and water absorption.

According to another study [5], due to the lightweight properties of EPS beads and their hydrophobic surface, EPS concrete is prone to segregation during casting, which results in poor workability and lower strength. In their study a "sand-wrapping" technique was used. The research showed that EPS concrete with a density of $800-1800 \mathrm{~kg} / \mathrm{m}^{3}$ and a compressive strength of 10-25 MPa can be made by partially replacing coarse and fine aggregate by EPS beads. Also,

\footnotetext{
* Corresponding author: bengin.masih@soran.edu.iq

$>$ This is an open access article under the CC-BY license (https://creativecommons.org/licenses/by/4.0/).

(C) Authors retain all copyrights.
} 
fine silica fume greatly improved the bond between the EPS beads and cement paste and increased the compressive strength of EPS concrete.

A recent published paper [6] deals with the mix design and mechanical properties of very lightweight concrete (LWC) made of EPS and very high performance matrix. In this paper, they added a super-plasticizer and adjusted the dosage. It is shown that the lower the inclusion size, the higher the compressive strength of the hardened concrete.

Another study [7] reports the results of an experimental investigation into the properties of hardened concrete bricks containing EPS beads. The beads are used as part of fine aggregate replacement in the mixes. It was found that EPS concrete is very prone to segregation and has low compressive strength. The properties of the bricks are mainly influenced by the content of EPS beads in the mix. The results indicate that polystyrene concrete mix with certain portion of the beads may provide as a suitable alternative material in the construction industry. The permeability was also decreasing with increasing density. It was interesting to see that the higher strength and higher density EPS concretes $\left(1500 \mathrm{~kg} / \mathrm{m}^{3}\right)$ were similar to control concretes in terms of permeability.

The total WA values in an investigation [8] show a decreasing trend with increasing density of the concretes. It was also observed that the lower the EPS bead size, the greater the concrete compressive strength, for the same concrete porosity. This is in agreement with the results obtained in a recent study [9] which confirmed that the volume of EPS has the most significant effect on compressive strength of concrete. The compressive strength of EPS concretes was found to be directly proportional to the concrete's density [9]. That means EPS concrete's compressive strength increases with an increase in concrete density. Another study [10] revealed that increasing the EPS content causes a significant reduction of thermal conductivity, fire resistance and compressive strength of concrete. Similar results have been reported elsewhere $[11,12]$. The compressive strength of EPS concrete increased as the EPS bead size decreased, and increased as the natural coarse aggregate increased. It was also shown that due to micro-cracks of shrinkage action in EPS concrete, water absorption of concrete by total and capillary action increases with an increase in EPS content in concrete. Another recent published study [13] reported the effect of EPS particles on mechanical and durability properties of self-compacting concrete and showed that EPS mixes in salt/wetting curing condition mostly has higher levels of compressive strength. They also reported that the concrete containing EPS categorized as "good" concrete quality.

The novel technique of densifying EPS to produce a novel lightweight aggregate (LWA) was explained earlier [14] and the effects of this novel aggregate on different properties of concrete have been investigated. Although, research on LWAC containing EPS has intensified in the last decade however, there are still gaps in our knowledge of the properties and behaviour of EPS concrete. One reason is that EPS concrete properties can vary considerably depending on the type of EPS and the technique of waste EPS recycling used, and so any conclusions may only be valid for the specific cases studied. There is not much information in the literature on the absorption characteristics of LWAC containing EPS by capillary action using this novel recycling technique. Therefore, the present experimental study was aimed at investigating capillary water absorption (CWA) and strength of concretes as a function of water/cement (W/C) ratio, curing time and replacement level.

\section{Experimental Procedure}

\subsection{Materials and Mixtures}

The cement used was ordinary Portland cement or Type I. The chemical composition of cement is given in Table 1. The natural aggregate used was a low-cost crushed limestone ranges between 0 and $8 \mathrm{~mm}$ in size conforming to the British standard requirements with bulk density of $1673 \mathrm{~kg} / \mathrm{m}^{3}$, specific gravity (SSD) of 2.67 and water absorption (24 h) of $1.1 \%$. The particle size distributions (sieving) details of natural and the novel LWA called stabilised polystyrene (SPS) according to BS EN 933-1. (2012) [15] are presented in Figure 1. and Table 2. The manufacturing process of SPS aggregates has been described earlier [14]. The novel aggregate used was a waste-EPS based LWA with bulk density of $457 \mathrm{~kg} / \mathrm{m} 3$, specific gravity (SSD) of 0.8 and water absorption $(24 \mathrm{~h})$ of $13 \%$. It is worth to mention here that, generally LWAs have high porosity resulting in higher water absorption (WA) compared with natural aggregates. In the case of SPS aggregate, due to the coating (10\% clay \& $10 \%$ cement) of EPS particles, WA of SPS is higher than natural aggregate and when mixed with water the value of volumetric paste content is increased.

Table 1. Chemical compositions of Portland cement

\begin{tabular}{cccccccccccc}
\hline Constituent & $\mathrm{SiO}_{2}$ & $\mathrm{Al}_{2} \mathrm{O}_{3}$ & $\mathrm{Fe}_{2} \mathrm{O}_{3}$ & $\mathrm{CaO}$ & $\mathrm{MgO}$ & $\mathrm{SO}_{3}$ & $\mathrm{~K}_{2} \mathrm{O}$ & $\mathrm{Na}_{2} \mathrm{O}$ & $\mathrm{Cl}$ & LOI & Compressive Strength (28-day) \\
\hline Value (\%) & 22.8 & 3.8 & 1.4 & 66.5 & 0.8 & 3.3 & 0.7 & 0.1 & $<0.1$ & 1.5 & $75.5 \mathrm{MPa}$ \\
\hline
\end{tabular}


Table 2. Particle size distribution of aggregates

\begin{tabular}{|c|c|c|c|c|c|c|c|c|c|c|c|}
\hline \multicolumn{2}{|c|}{ Sieve size (mm) } & \multirow{2}{*}{$\begin{array}{c}\mathbf{0 . 0 6 3} \\
0.00\end{array}$} & \multirow{2}{*}{$\begin{array}{r}\mathbf{0 . 1 2 5} \\
6.19\end{array}$} & \multirow{2}{*}{$\begin{array}{l}\mathbf{0 . 2 5} \\
10.77\end{array}$} & \multirow{2}{*}{$\begin{array}{c}\mathbf{0 . 5} \\
16.45\end{array}$} & \multirow{2}{*}{$\begin{array}{c}\mathbf{1} \\
25.35\end{array}$} & \multirow{2}{*}{$\begin{array}{c}2 \\
40.68\end{array}$} & \multirow{2}{*}{$\begin{array}{c}\mathbf{4} \\
59.70\end{array}$} & \multirow{2}{*}{$\begin{array}{c}\mathbf{8} \\
86.54\end{array}$} & \multirow{2}{*}{$\begin{array}{c}\mathbf{1 0} \\
95.12\end{array}$} & \multirow{2}{*}{$\begin{array}{r}\mathbf{1 2 . 5} \\
100\end{array}$} \\
\hline & SPS & & & & & & & & & & \\
\hline & NA & 0.00 & 3.49 & 15.77 & 50.53 & 63.42 & 75.84 & 94.41 & 97.79 & 100 & 100 \\
\hline
\end{tabular}

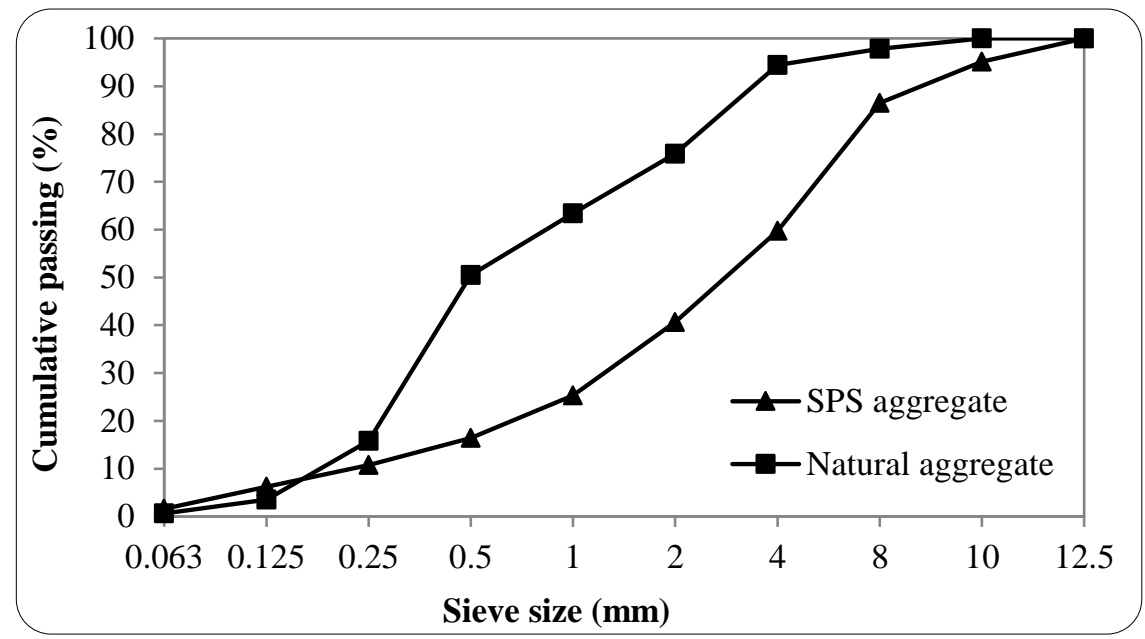

Figure 1. Particle size distribution of aggregates

Total of twelve different concrete mixtures were made for this investigation. The control mixture for each Series had a proportion of 1 (cement): 6 (Natural aggregate). The natural aggregate was replaced with 0, 30, 60 and 100\% (by volume) of SPS aggregate. The water to cement ratios (W/C) of 0.6, 0.8 and 1.0 were used for three different series. Superplasticiser has not been used in the present study to minimise cost. Further details about the mixtures are presented in Table 3.

Table 3. Details of mixtures

\begin{tabular}{|c|c|c|c|c|c|c|}
\hline \multirow{2}{*}{$\begin{array}{c}\text { Series } \\
\text { No. }\end{array}$} & \multirow{2}{*}{ W/C } & \multirow{2}{*}{$\begin{array}{l}\text { Mix } \\
\text { No. }\end{array}$} & \multirow{2}{*}{ SPS $(\%)$} & \multicolumn{3}{|c|}{ Mixture Constituents $\left(\mathbf{k g} / \mathbf{m}^{3}\right)$} \\
\hline & & & & Cement & Water & $\mathbf{N A}+\mathbf{S P S}$ \\
\hline \multirow{4}{*}{1} & \multirow{4}{*}{0.6} & 1 & $0(\mathrm{C} 1)$ & 320 & 192 & $1920+0$ \\
\hline & & 2 & 30 & 320 & 192 & $1344+173$ \\
\hline & & 3 & 60 & 320 & 192 & $768+345$ \\
\hline & & 4 & 100 & 320 & 192 & $0+575$ \\
\hline \multirow{5}{*}{2} & \multirow{5}{*}{0.8} & 5 & $0(\mathrm{C} 2)$ & 320 & 256 & $1920+0$ \\
\hline & & 6 & 30 & 320 & 256 & $1344+173$ \\
\hline & & & & & & \\
\hline & & 7 & 60 & 320 & 256 & $768+345$ \\
\hline & & 8 & 100 & 320 & 256 & $0+575$ \\
\hline \multirow{4}{*}{3} & \multirow{4}{*}{1.0} & 9 & $0(\mathrm{C} 3)$ & 320 & 320 & $1920+0$ \\
\hline & & 10 & 30 & 320 & 320 & $1344+173$ \\
\hline & & 11 & 60 & 320 & 320 & $768+345$ \\
\hline & & 12 & 100 & 320 & 320 & $0+575$ \\
\hline
\end{tabular}

Concrete was mixed in a planetary mixer of 100-litres capacity. It was cleaned and slightly damped with a wet cloth to avoid any absorption of water by the concrete mixer. First, SPS aggregate was wetted with $1 / 3$ of the mixing water 
before adding the remaining materials. It should be noted that extra water was added to the mixture to compensate for the water absorption of SPS and other aggregates. Natural aggregate, cement and SPS aggregates were then gently poured into the mixer according to the calculated quantities. Once all the dry materials were inside the mixer, the remaining water was then poured slowly while mixing continued. After 3-5 minutes of thorough mixing (until the mix was homogenous) the mixing was stopped and the slump and flow tests were carried out to assess the consistence of concrete. Specimens were cast in steel moulds. Before casting began, the moulds were visually inspected and cleaned thoroughly. Thereafter, a thin layer of oil was applied to the inside surfaces of the moulds for easy de-moulding. Concrete was poured into the moulds in three layers and each layer compacted by using a steel tamping rod. Subsequently, a trowel was used to level the top surfaces and neatly trim them as best as possible. After casting, specimens were covered with plastic sheets and left in the laboratory for 24 hours. Then de-moulding took place and specimens were placed in water for different curing periods $(1,7,28,360$ and 720 days). Each of the results reported in the present study were average results of three specimens. However, if the variation between the three values was more than $10 \%$, an additional specimen was tested to find this average. Although a new method [14] was used in the manufacturing process of SPS aggregate to improve the EPS particles' resistance to segregation, care was also exercised during mixing, pouring and compacting of the fresh concrete.

\subsection{Testing Procedure}

\subsubsection{Workability and Density}

The workability of the fresh concretes was measured by slump-test (Figure 2) according to BS EN 12350-2:2009 [16] on the mixtures of Series 1, 2 and 3, and a flow test was carried out on the mixtures in Series 3 only. The inside of the slump cone was slightly damped with a wet cloth to avoid water absorption by the cone. The cone was then placed on a solid, impermeable base and filled with three equal layers of fresh concrete. To ensure compaction, each layer was compacted 25 times with the tamping rod. After the third layer was compacted, the tamping rod was rolled over the top so that it was finished off level with the top of the cone. The flow test (Figure 3 ) is used for high workability concrete (e.g. with a slump of $175 \mathrm{~mm}$ or more). The test is carried out in accordance with BS EN 12350-5:2009 [17]. A cone, similar to that used for slump testing but truncated, is filled with concrete in two layers. Each layer is tamped 10 times with a special wooden bar and the concrete of the upper layer is finished off level with the top of the cone. Any excess is cleaned off the outside of the cone. The cone is then raised allowing the concrete to flow out and spread out a little on the flow table. The table top is then raised until it meets the stop and allowed to drop freely 15 times over a period of 45-75 seconds. This causes the concrete to spread further, in a roughly circular shape. Flow is measured as the average diameter in both directions of the concrete and the mean is taken as the flow value in centimetre. The dry density of concrete specimens which can control many physical properties in LWC and is mainly controlled by the volume and density of LWA was measured according to BS EN 12390-7:2009 [18].

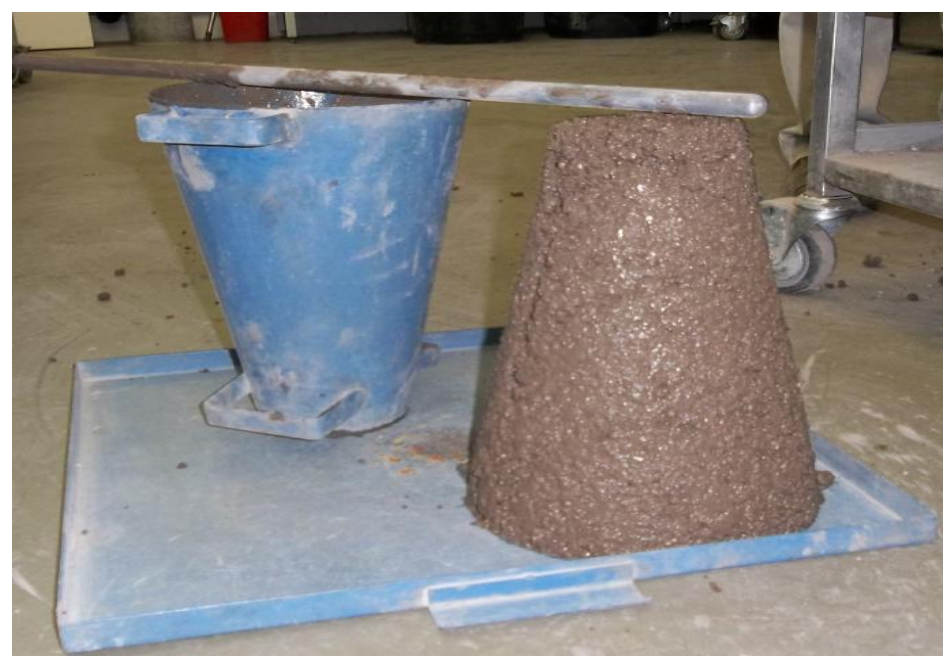

Figure 2. Slump test 


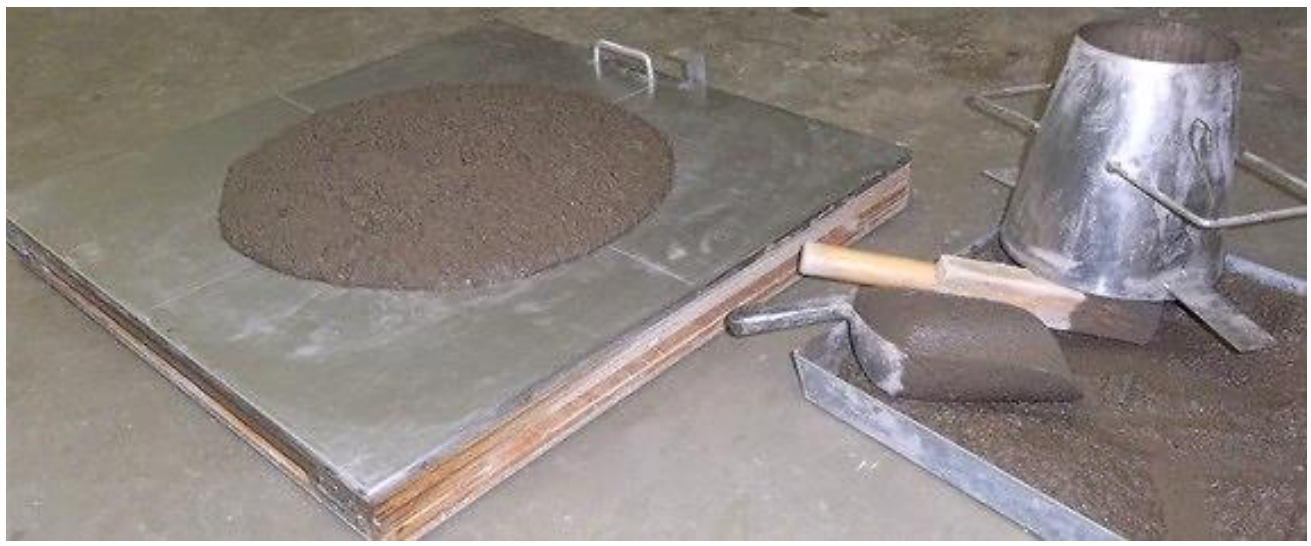

Figure 3. Flow table test

\subsubsection{Compressive Strength}

Cubes of $100 \mathrm{~mm}$ size were used for the determination of compressive strength in conformity with BS EN 123903:2009 [19] at 1, 7, 28, 360 and 720 days. A compressive strength test was carried out using a testing machine (Figure 4) of $3000 \mathrm{kN}$ capacity at the loading rate of $0.6 \mathrm{MPa} / \mathrm{s}$ according to BS EN 12390-4:2000 [20].

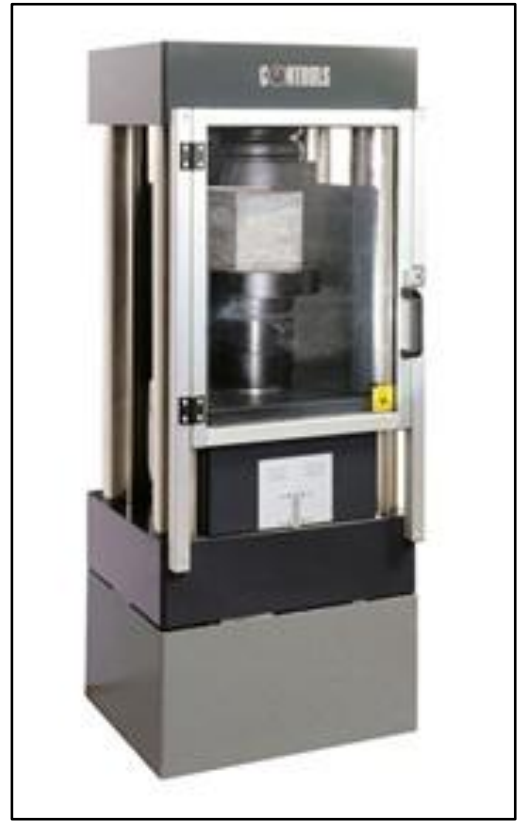

Figure 4. Compression machine

\subsubsection{Total Water Absorption}

Prisms of $100 \times 100 \times 50 \mathrm{~mm}$ size were used for the total water absorption (WA) test. These specimens were cured in water until testing. Saturated surface-dry (SSD) prisms were kept in an oven at a lower temperature of $80^{\circ} \mathrm{C}$ until a constant weight was attained. This is because EPS is extremely sensitive to thermal degradation when subjected to relatively high temperatures. These were then immersed in water (Figure 5) and the weight gain was measured at regular intervals until a constant weight was reached. This normally took 48 hours. The absorption at 30 minutes and the final (total) absorption (at a point when the difference between two consecutive weights was almost negligible) were reported to assess the concrete quality. The WA is given by:

$$
W A(\%)=\frac{W_{s}-W_{d}}{W_{d}} \times 100
$$

Where $\mathrm{W}_{\mathrm{s}}$ and $\mathrm{W}_{\mathrm{d}}$ are the saturated and dry weight of specimens, respectively. 


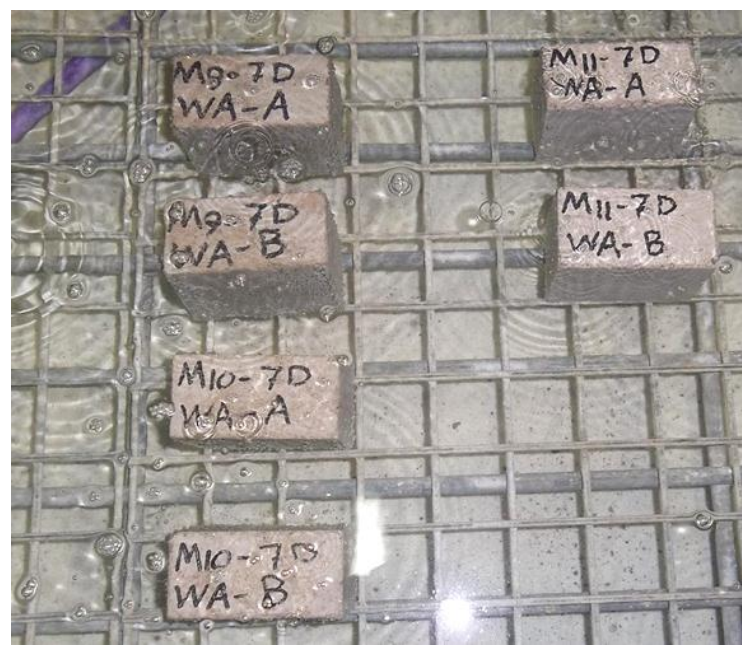

Figure 5. Total water absorption test

\subsubsection{Capillary Water Absorption}

Specimens of $100 \times 100 \times 50 \mathrm{~mm}$ size were used for the CWA test (Figure 6 ). These specimens were cured in normal water until testing. Saturated surface dry (SSD) specimens were kept in a hot air oven at $80^{\circ} \mathrm{C}$ until a constant weight was attained. For the CWA test, the absorption of water by the concrete specimens was determined by measuring the increase in the mass resulting from water absorption as a function of time when only one surface $(2-3 \mathrm{~mm})$ of the specimen is exposed to water on a support device $[2,21]$. The schematic diagram of the CWA (moisture migration) test setup used is shown in Figure 7. During the test period, weight gain was monitored at intervals of 1, 3, 5, 7, 10, 20, 30, 45, 60, 120, 180, 1440 and 2880 minutes. The water level was kept constant throughout the test. The CWA values are the average of three test samples. The weight $(\mathrm{g})$ of water absorbed per unit area $\left(\mathrm{mm}^{2}\right)$ was plotted against the square root of time (minute). The units are in $\mathrm{g} / \mathrm{mm}^{2} \min ^{1} / 2$.

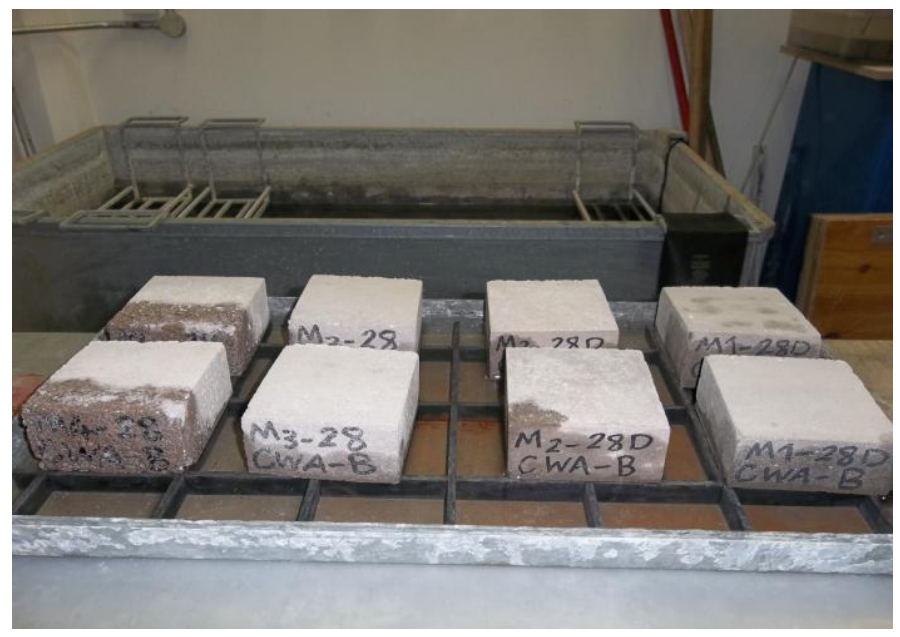

Figure 6. Capillary water absorption test

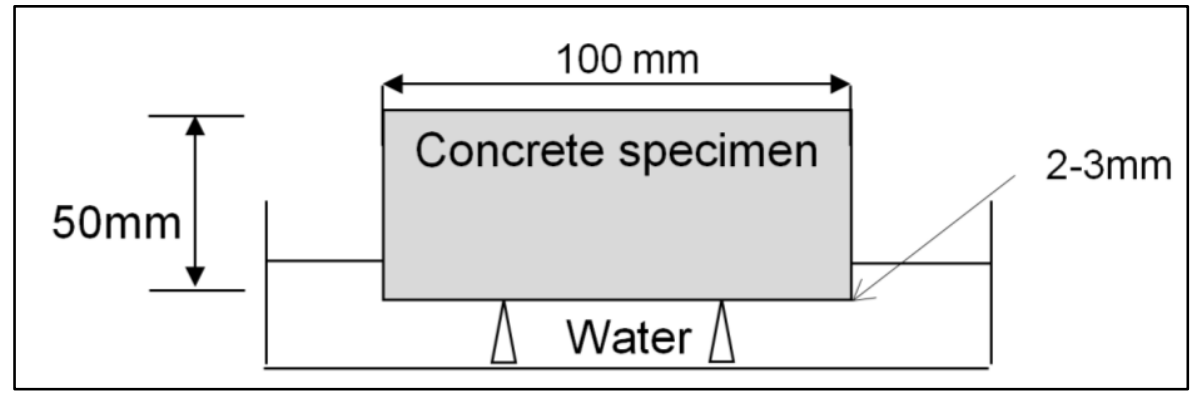

Figure 7. Diagrammatic of CWA test setup

\section{Results and Discussion}

\subsection{Workability and Density}

The workability (slump and flow table) values for concretes containing varying amounts of SPS aggregate at different 
water to cement ratios (W/C) are presented in Table 4. Comments on visual observation are also included in the table. The slump values were in the range of 3-36mm in Series 2 and 55-160 $\mathrm{mm}$ in Series 3. None of the mixtures in Series 1 recorded any slump, which means they were stiff mixes. This was mainly due to the low W/C ratio and lack of any super-plasticiser which would have improved the workability [6, 22, 23]. Flow values for Series $3(\mathrm{~W} / \mathrm{C}=1.0) \mathrm{mixes}$ were in the range of 38-48 cm. The workability for the mixtures of the Series 1 was just enough to be compacted and could also be finished, but all other mixtures were flexible and easy to work with, and compaction and finishability were easy.

Table 4. Workability of concrete containing varying amounts of SPS at different W/C ratios

\begin{tabular}{|c|c|c|c|c|c|c|c|}
\hline \multirow{3}{*}{ Series No. } & \multirow{3}{*}{$\mathrm{W} / \mathrm{C}$} & \multirow{3}{*}{$\begin{array}{l}\text { Mix } \\
\text { No. }\end{array}$} & \multicolumn{2}{|c|}{ Workability } & \multirow{3}{*}{ Dry density $\left(\mathrm{kg} / \mathrm{m}^{3}\right)$} & \multirow{2}{*}{\multicolumn{2}{|c|}{$\begin{array}{c}\text { Visual } \\
\text { Observation }\end{array}$}} \\
\hline & & & \multirow{2}{*}{$\begin{array}{l}\text { Slump } \\
(\mathrm{mm})\end{array}$} & \multirow{2}{*}{$\begin{array}{l}\text { Flow } \\
(\mathrm{cm})\end{array}$} & & & \\
\hline & & & & & & $\mathrm{S}$ & B \\
\hline \multirow{4}{*}{1} & \multirow{4}{*}{0.6} & 1 & 0 & - & 2133 & $\mathrm{~N}$ & $\mathrm{~N}$ \\
\hline & & 2 & 0 & - & 1961 & $\mathrm{~N}$ & $\mathrm{~N}$ \\
\hline & & 3 & 0 & - & 1637 & $\mathrm{~N}$ & $\mathrm{~N}$ \\
\hline & & 4 & 0 & - & 1020 & $\mathrm{~N}$ & $\mathrm{~N}$ \\
\hline \multirow{4}{*}{2} & \multirow{4}{*}{0.8} & 5 & 3 & - & 2074 & $\mathrm{~N}$ & $\mathrm{~L}$ \\
\hline & & 6 & 20 & - & 1814 & $\mathrm{~N}$ & $\mathrm{~L}$ \\
\hline & & 7 & 36 & - & 1537 & $\mathrm{~N}$ & $\mathrm{~L}$ \\
\hline & & 8 & 15 & - & 1009 & $\mathrm{~N}$ & $\mathrm{~L}$ \\
\hline \multirow{4}{*}{3} & \multirow{4}{*}{1.0} & 9 & 55 & 46 & 1989 & $\mathrm{~N}$ & $\mathrm{M}$ \\
\hline & & 10 & 140 & 47 & 1742 & $\mathrm{~N}$ & M \\
\hline & & 11 & 160 & 48 & 1387 & $\mathrm{~N}$ & M \\
\hline & & 12 & 70 & 38 & 891 & $\mathrm{~N}$ & M \\
\hline
\end{tabular}

S: Segregation; B: bleeding; N: no; L: low; M: moderate.

The workability of the concretes increased with increasing the replacement level of SPS aggregate in concrete up to $60 \%$ then decreased for $100 \%$ SPS replacement. This was mainly due to the SPS aggregates high water absorption and lack of any superplasticiser, which would have improved the workability [24]. The generally high absorption capacity of LWAs reduces the workability of the mix due to the aggregates' higher porosity. However, the absorption capacity of polystyrene is very low due its closed cellular structure [25]. Nevertheless, in the present study the clay content (10\%) and cement (10\%) in SPS aggregates, which coated the polystyrene particles, possess a higher water absorption capacity than unmodified polystyrene particles. It is worth to mention here that lightweight (low-density) concrete does not show as much slump as normal-weight (normal density) concrete with the same workability. The reason for this, is that the effect of gravity is lower in the case of lighter aggregate [26-29].

The dry density of concretes (which complied with BS EN 12390-7:2009) [18] containing varying amounts of SPS aggregates is presented in Table 4 . The density values were in the range of $891-2133 \mathrm{~kg} / \mathrm{m}^{3}$. According to the results reported in Table 3, the density of concretes decreased with increasing the replacement level of SPS aggregate with natural aggregates. This is because the density of SPS aggregates was much less than that of natural aggregates. According to BS EN 206 (2000) [30] the LWC must have a dry density of not less than $800 \mathrm{~kg} / \mathrm{m}^{3}$ and not more than $2000 \mathrm{~kg} / \mathrm{m}^{3}$. Thus, the concrete containing 30\% SPS and more can be considered as LWC depending on SPS replacement levels in concrete.

\subsection{Compressive Strength}

The compressive strength of concretes containing 0, 30, 60 and 100\% SPS aggregate at different W/C ratios of 0.6, 0.8 and 1.0 and different water curing periods of 1, 7, 28,360 and 720 days is presented in Figure 8. The compressive strength values are in the range of 2.04-24.36, 1.18-19.12 and 0.64-14.31MPa for Series 1, Series 2 and Series 3, respectively.

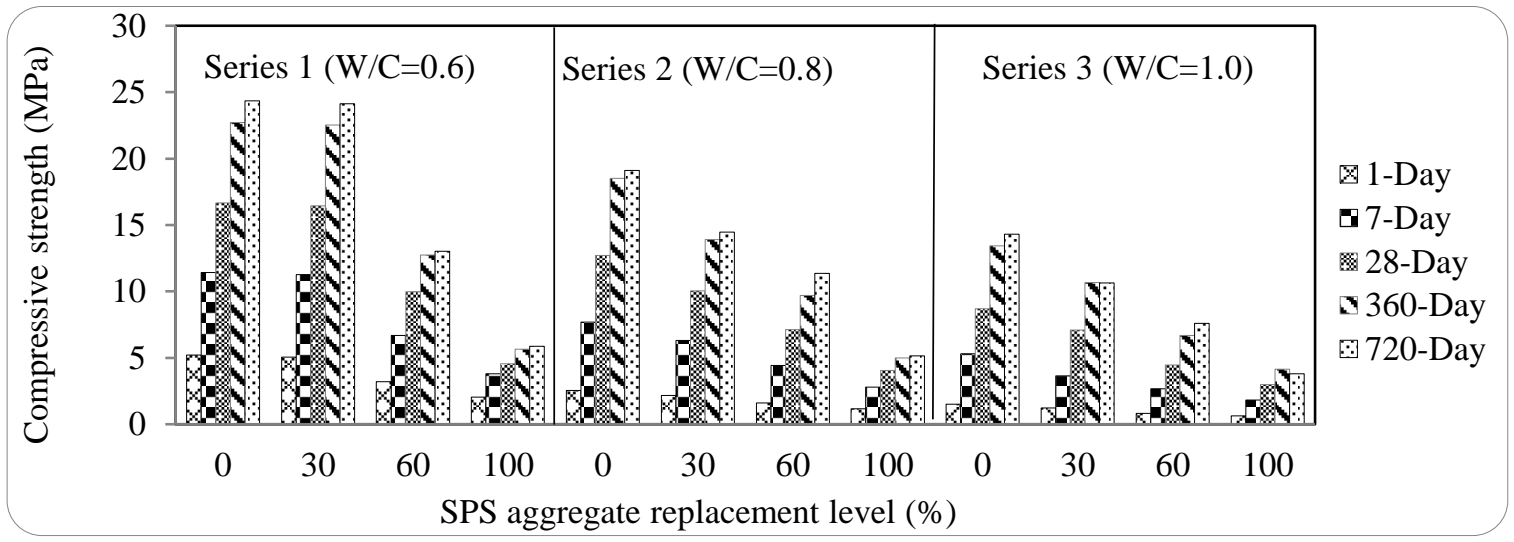

Figure 8. Compressive strength of concrete containing varying amounts of SPS aggregate at different W/C ratios and curing periods 
The results show that the incorporation of SPS aggregates caused a reduction in the compressive strength of concrete depending on the level of replacement with natural aggregate [14]. The compressive strength of the SPS concretes at 28 days decreased between 1-73\%, 21-68\% and 19-66\% at W/C ratios of 0.6, 0.8 and 1.0 respectively, compared to the control concrete of each series. It was interesting to see that there was no significant difference between the compressive strength of $30 \%$ SPS concrete and control concrete $(1 \%$ only) at $\mathrm{W} / \mathrm{C}=0.6$.

\subsection{Water Absorption}

The 30 minutes and total WA of concrete containing varying amounts of SPS aggregates at different curing times is presented in Figure 9. The WA values at 30 minutes and total for all three series varied between 1.6-19.6\% and 3.7$42.8 \%$ respectively, at 28 days of curing.

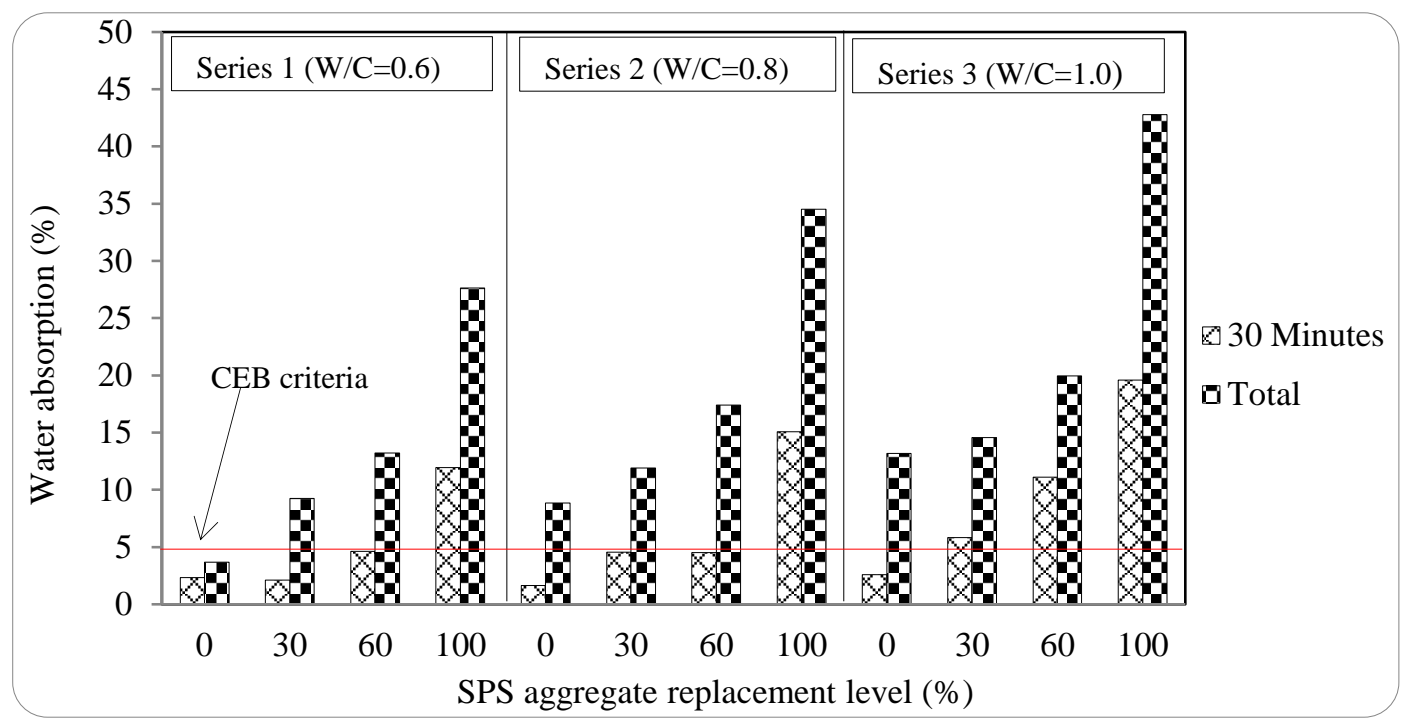

Figure 9. WA of concrete containing varying amounts of SPS

The concrete with a higher volume of SPS aggregate, showed higher absorption. Since the non-absorbent EPS is the main material in SPS aggregate production, WA mainly increased as a result of the combination of the highly porous interfacial transition zone (ITZ) between the EPS and the stabilising coating and; the highly porous coating of SPS aggregates in comparison to the cement paste of mixture [14]. This can be confirmed from the higher water absorption of low density concretes. In the case of SPS aggregate, due to the coating (10\% clay \& $10 \%$ cement), WA of SPS is higher than natural aggregate and when mixed with water the value of volumetric paste content is increased. A recent published study [31] reported that the properties of the LWAC, including the transferring property, will be improved by lowering the W/C ratio and adding super-plasticiser. According to an investigation [32], for higher W/C ratios, fewer surfaces are covered by the aggregates, so when decreasing the amount of paste, the voids or pores in the concrete increase and so does the water absorption.

According to the 30 minutes WA values and compared with the CEB [33] assessment criteria, LWAC containing $60 \%$ SPS aggregates, indicating an "average" quality concrete. In addition, mixes with 100\% SPS percentages showed higher absorption values at the initial stage (30 minutes) and total absorption compared to the concretes containing lower SPS aggregates. WA for the concretes made with SPS aggregate in the present study varied between 9.5-44.8\%. Similar results have been reported on LWACs incorporating different types of LWAs with similar densities and cement content [4, 34-36].

Figure 10. shows the correlation between compressive strength and WA. An exponential function seems to better describe the correlation between two properties Where, $\mathrm{Y}$ is the compressive strength (MPa) and X is the WA (\%).

$$
Y=24.905 e^{-0.048 X}, \quad \mathrm{R}^{2}=0.9
$$

The value $\left(\mathrm{R}^{2}=0.9\right)$ represents a good correlation between the two compared parameters of strength and WA. It can be observed that the WA increases with a decrease in compressive strength and it also increases with an increase in SPS aggregate content. 


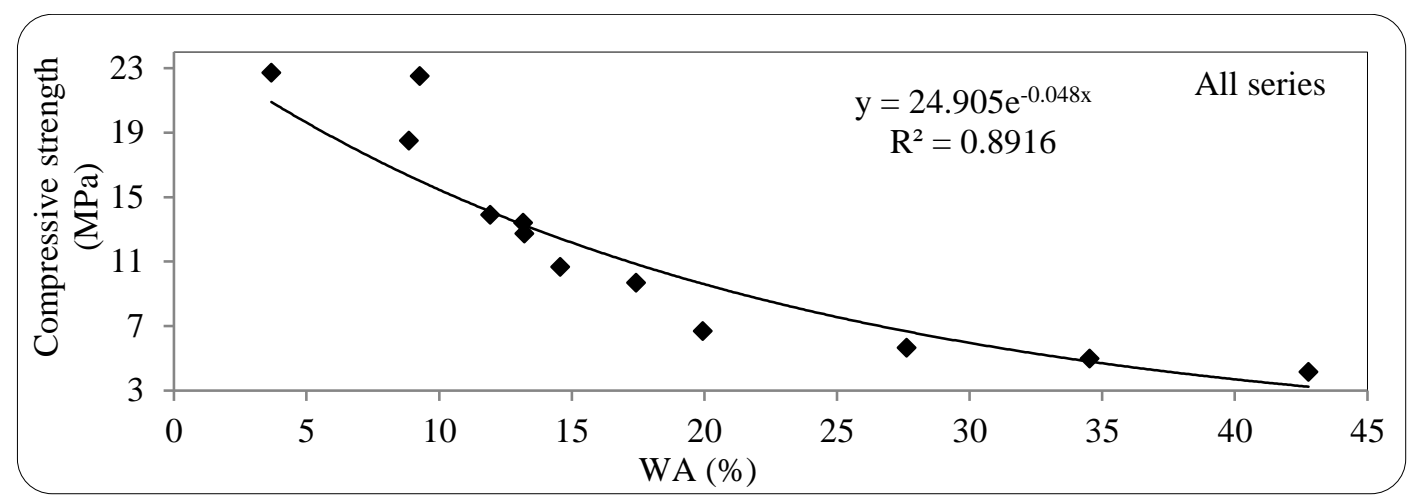

Figure 10. Correlation between compressive strength and WA of concrete containing varying amounts of SPS aggregate

\subsection{Capillary Water Absorption}

The amount of water absorbed per unit area for concrete containing varying amounts of SPS aggregate versus the square root of time at the ages of $1,7,28$ and 360 days of curing for Series $1(\mathrm{~W} / \mathrm{C}=0.6), 2(\mathrm{~W} / \mathrm{C}=0.8)$ and $3(\mathrm{~W} / \mathrm{C}=1.0)$ is shown in Figures 11-13, respectively. Capillary Water Absorption (CWA) of concrete is the phenomenon by which water is absorbed into concrete by capillary action as mentioned before $[2,3]$. Generally, there is a higher amount of water uptake with an increase in SPS content or decrease in concrete density at the end of the test period. However, there is no significant difference between the CWA of concrete mixtures during the first 5 minutes of the test for all series and at all curing periods except 360 days' age. The water uptake by capillary action is decreased as the curing period is increased and as can be expected the CWA increased along with the W/C ratio of the mixtures. When the W/C ratios are higher, there is an excess of water that does not participate in the water-cement reaction, so very small capillaries are produced and when the water evaporates, those empty spaces rest resistance to the concrete [32, 37, 38].

Mixtures containing 60 and 100\% SPS as a replacement for natural aggregate show substantially higher water uptake at the end of the testing period compared with mixtures containing 0 and $30 \%$ SPS. Due to the porous nature and shrinkage of the EPS particles of the SPS aggregate, the concrete connected porosity increased and resulted in higher CWA. Despite using a non-absorbent material of EPS in the SPS aggregate production process, similar to the water absorption test, the higher CWA of SPS aggregate concretes may be due to the shrinkage of EPS particles, lower cement content and higher W/C ratio. For example, at 360 days of curing, the water uptake at the end of the Series 1 (W/C=0.6) test period by the mix containing $100 \%$ SPS is nearly 2 times more than that of the reference mix (control concrete). Also at 1 day of curing nearly all mixtures did not appear to absorb more water towards the end of the test period (i.e. the last part of the curve is almost horizontal), whereas at the other curing ages the samples were still absorbing water. The ongoing hydration of concretes beyond 1 day of curing may cause blockage of pores and water would take a longer time to be absorbed.

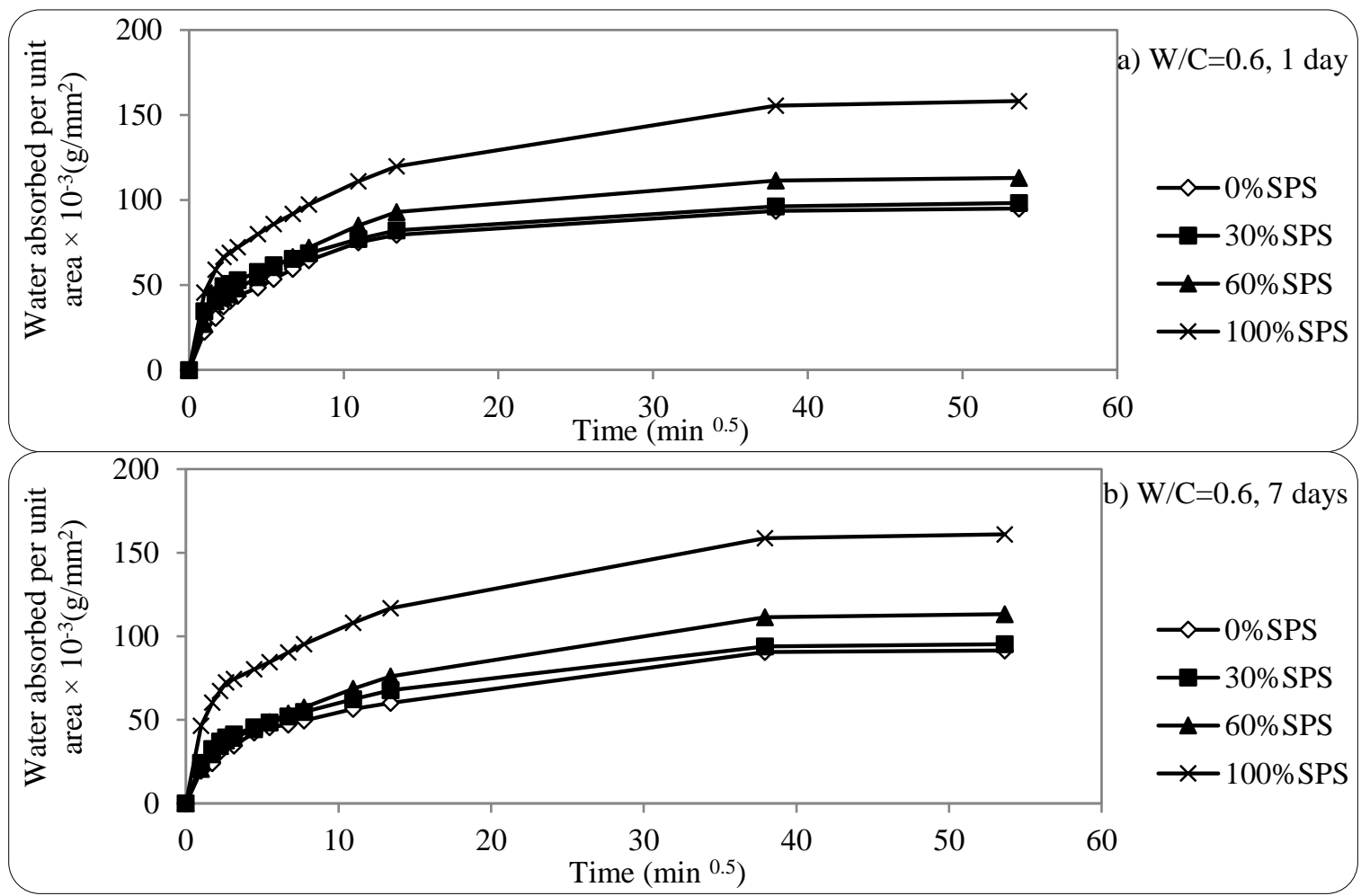




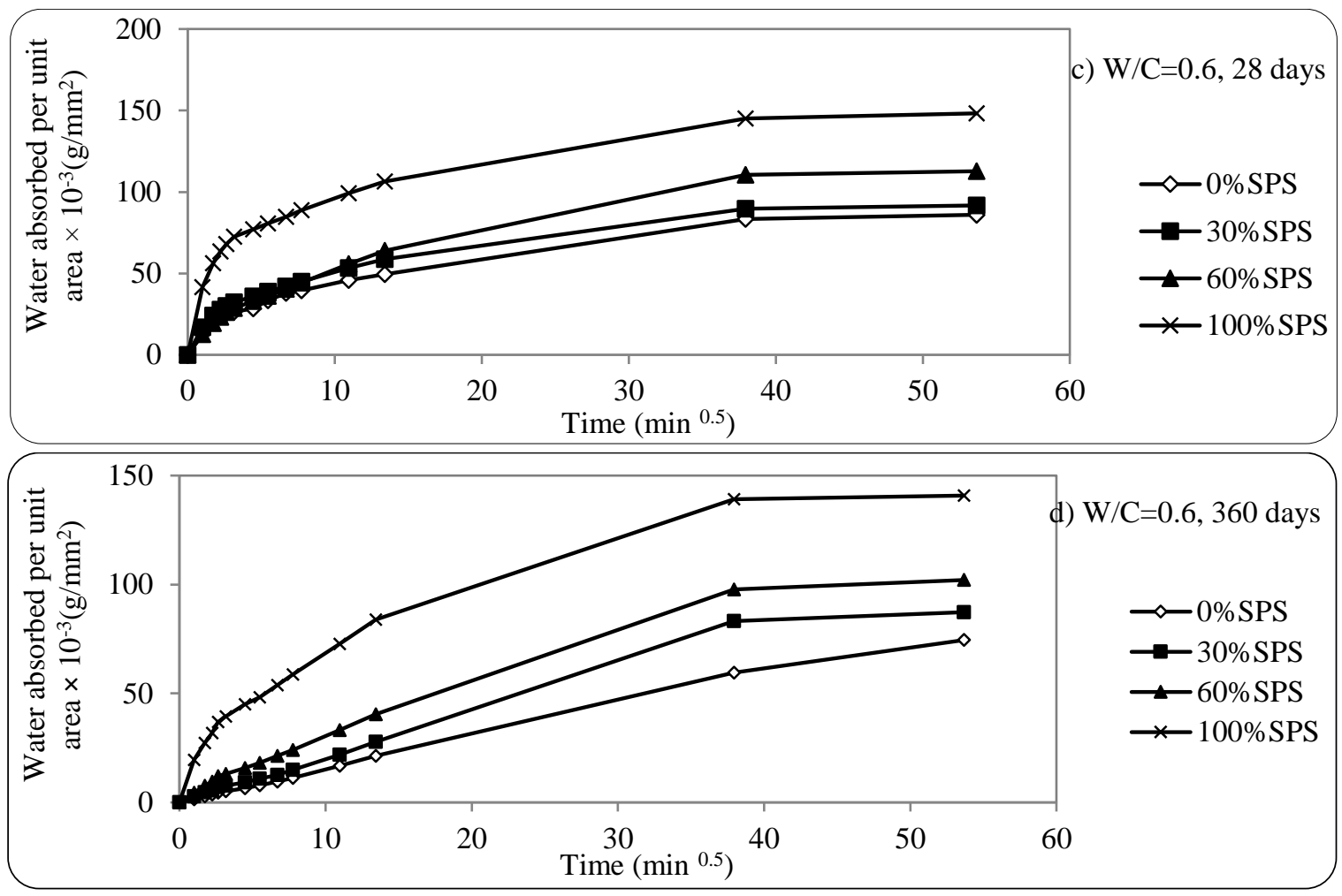

Figure 11. Water absorbed by capillary action for concretes containing varying amounts of SPS at different curing times (Series 1)

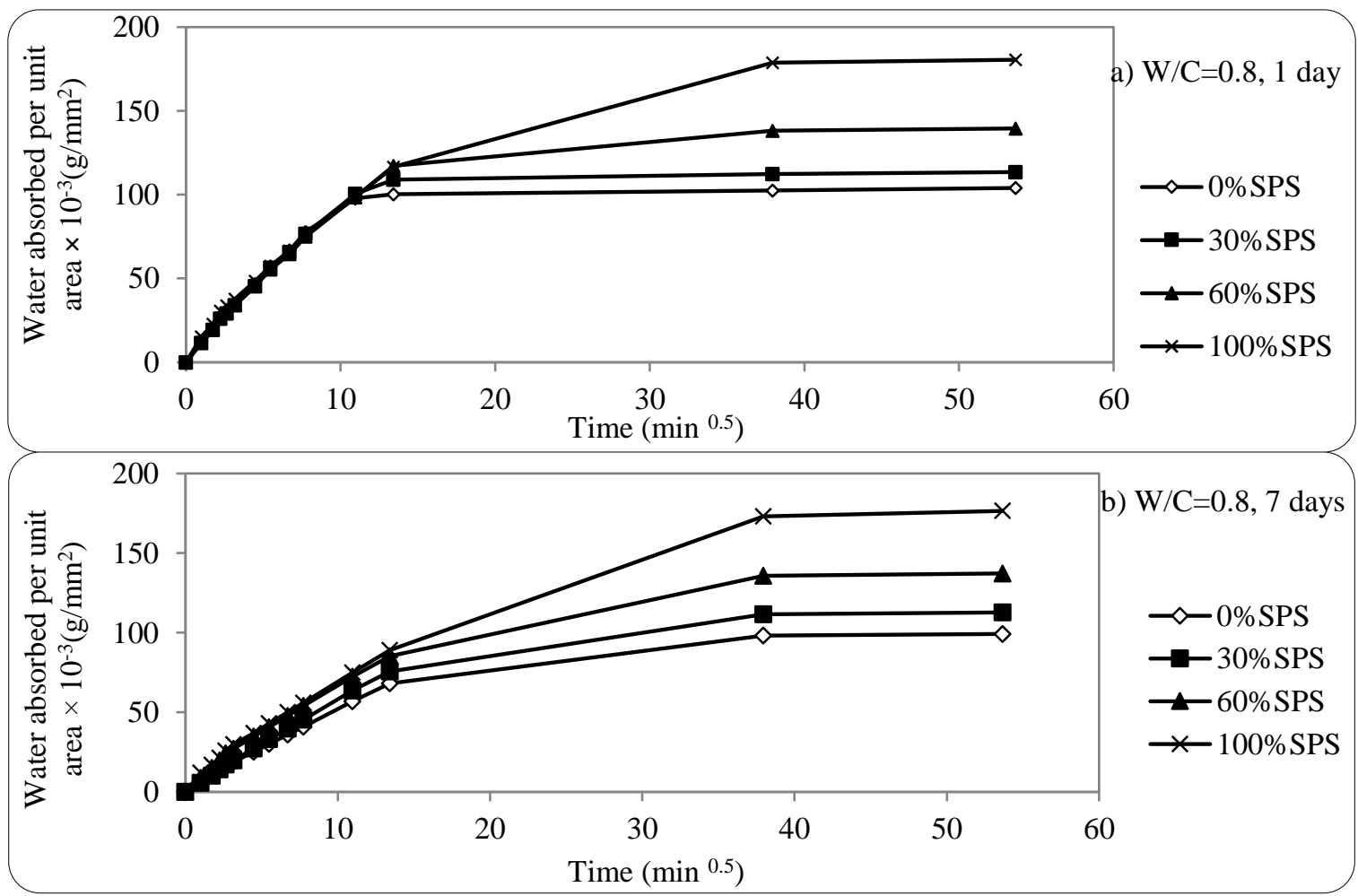



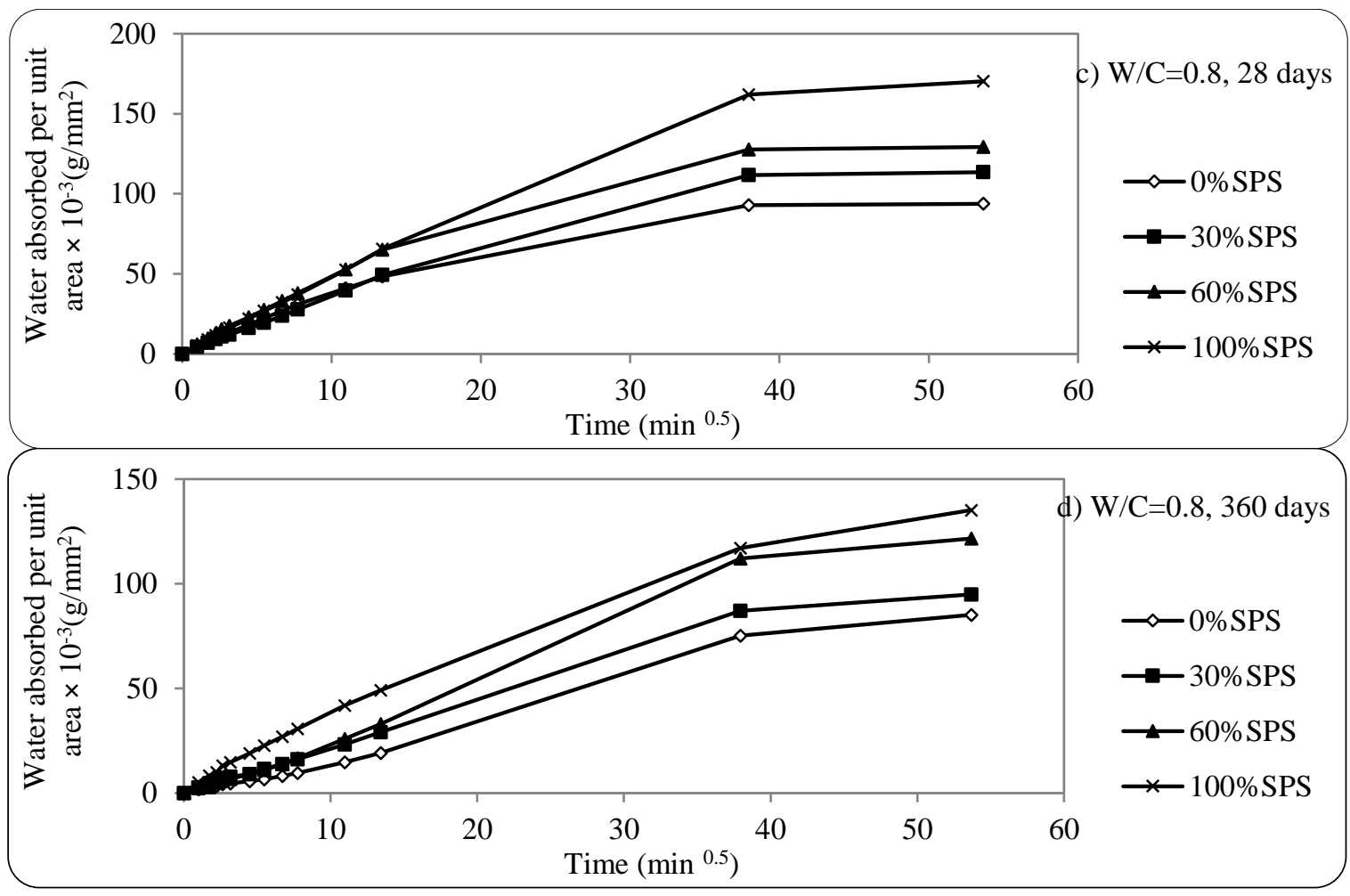

Figure 12. Water absorbed by capillary action for concretes containing varying amounts of SPS at different curing times (Series 2)

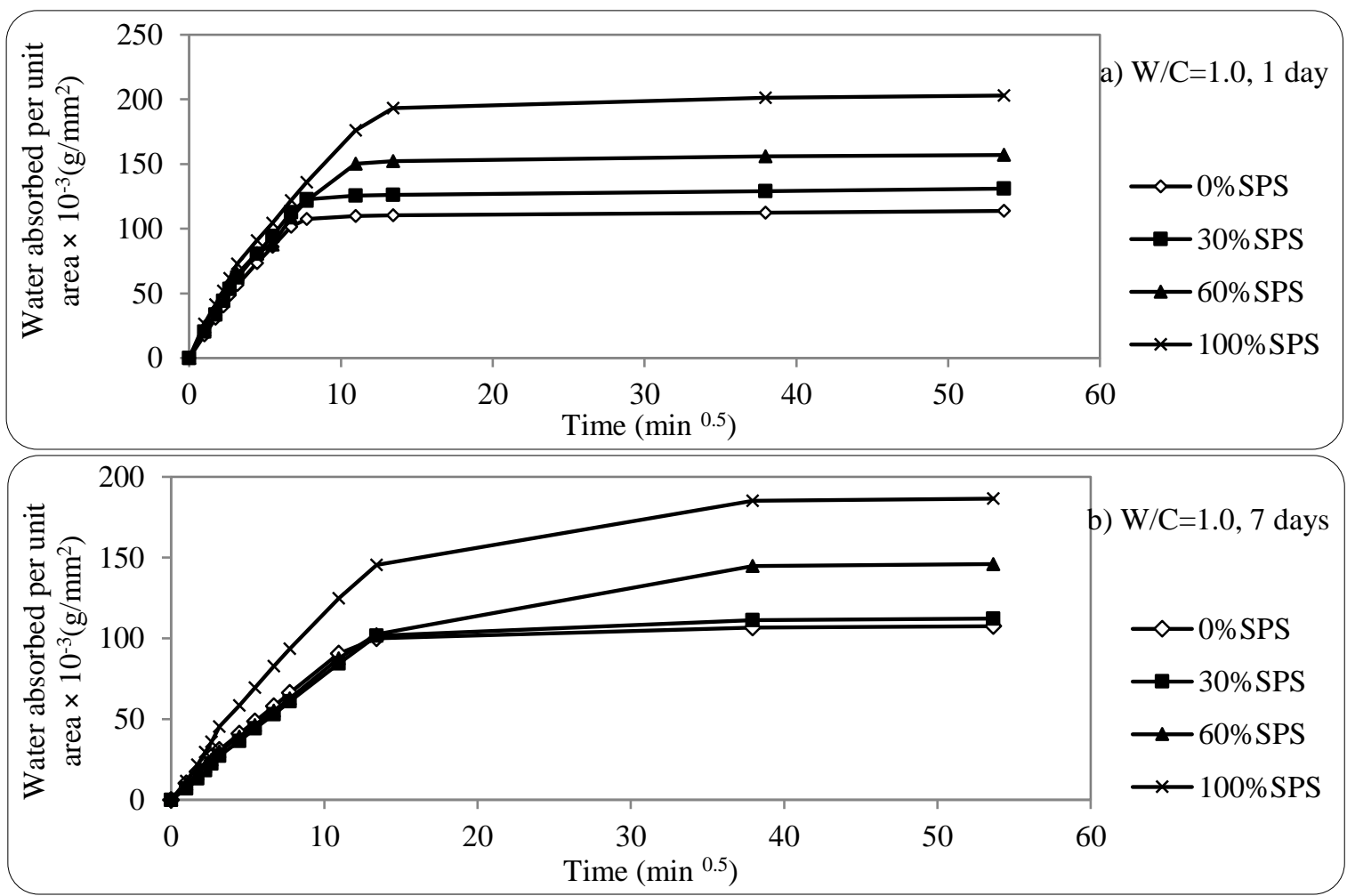




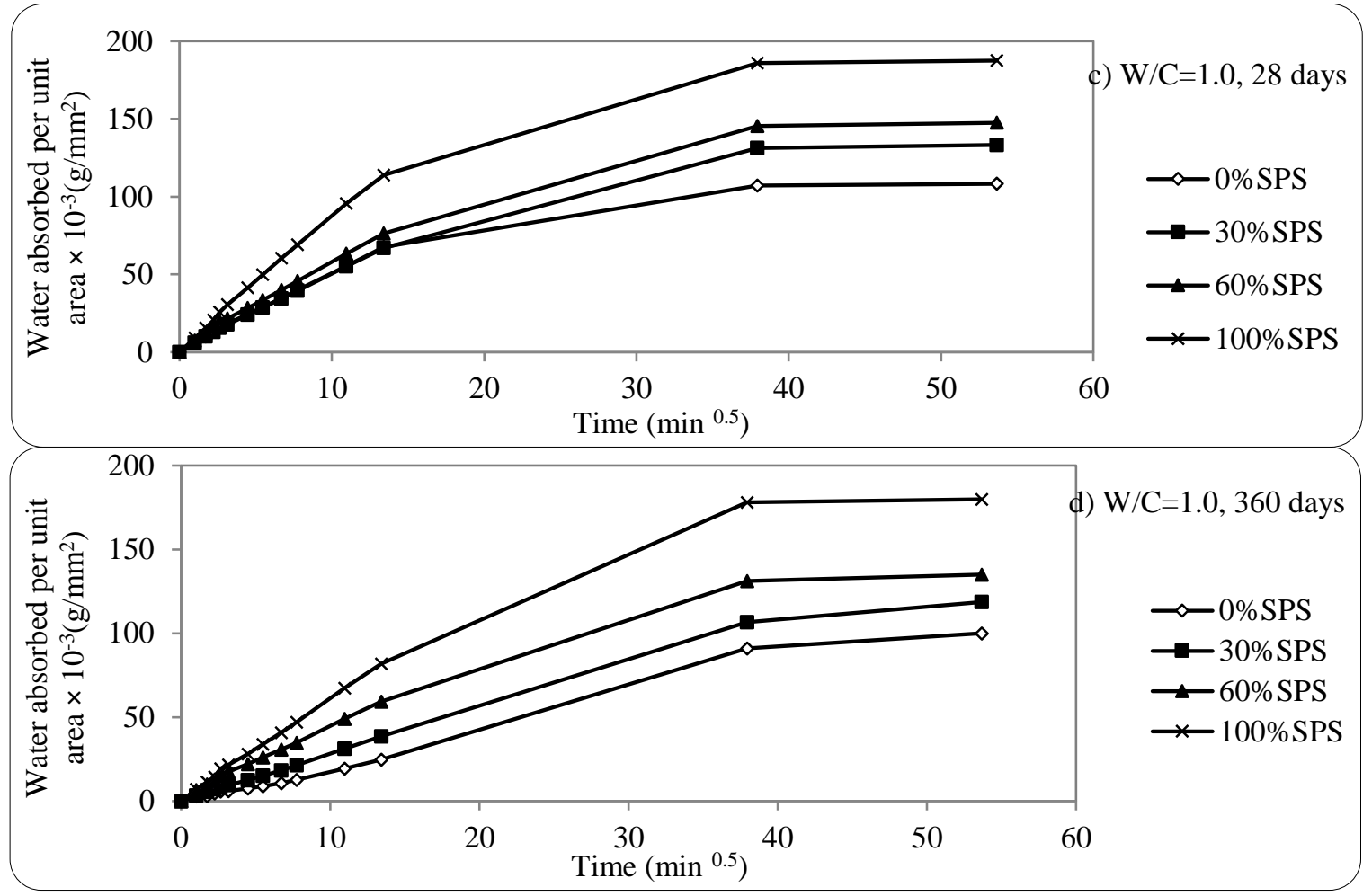

Figure 13. Water absorbed by capillary action for concretes containing varying amounts of SPS at different curing times (Series 3)

The rate of initial water absorption, which is referred to as the Water Absorption Coefficient (WAC) and expressed as the slope of the initial part of the curve during CWA [2, 3] is shown in Figure 14. for all mixtures (with and without SPS) at all curing periods. The WAC is generally higher when the SPS content in the mixture increases, as expected. In addition, and as can be expected, after 1 day of curing, the WAC is noticeably larger than after the other curing periods. Beyond 7 days of curing, the WAC reduces for all mixtures. Figure 8. also indicates that there is an exponential relationship between the WAC and the percentage of SPS in the mixtures at the different curing periods. If an exponential equation is fitted to the experimental data, the following equations (Equations 3-14) are obtained for W/C $=0.6,0.8$ and 1.0 at the various curing periods (Table 5); however more experimental data would be required to confirm the equations obtained:

Table 5. Correlation's equations between WAC and SPS percentages for different curing times

\begin{tabular}{cccc}
\hline Series No. & Equation No. & Equation & $\mathrm{R}^{2}$ \\
\hline \multirow{3}{*}{ Series 1 } & 3 & $Y(1$ day $)=13.968 e^{0.0034 X}$ & $R^{2}=0.7379$ \\
& 4 & $Y(7$ days $)=10.862 e^{0.0057 X}$ & $R^{2}=0.8772$ \\
& 5 & $Y(28$ days $)=9.1052 e^{0.007 X}$ & $R^{2}=0.6706$ \\
& 6 & $Y(360$ days $)=1.7877 e^{0.0183 X}$ & $R^{2}=0.9600$ \\
\hline \multirow{2}{*}{ Series 2 } & 7 & $Y(1$ day $)=14.008 e^{0.001 X}$ & $R^{2}=0.9836$ \\
& 8 & $Y(7$ days $)=8.1055 e^{0.0025 X}$ & $R^{2}=0.4842$ \\
& 9 & $Y(28$ days $)=5.1733 e^{0.0025 X}$ & $R^{2}=0.4600$ \\
Series 3 & 10 & $Y(360$ days $)=1.8728 e^{0.0091 X}$ & $R^{2}=0.7790$ \\
\hline 12 & $Y(1$ day $)=22.314 e^{0.0012 X}$ & $R^{2}=0.7427$ \\
& 13 & $Y(7$ days $)=10.626 e^{0.0039 X}$ & $R^{2}=0.5192$ \\
& 14 & $Y(36$ days $)=6.801 e^{0.0046 X}$ & $R^{2}=0.8026$ \\
& 13 days $)=2.0775 e^{0.0147 X}$ & $R^{2}=0.8837$ \\
\hline
\end{tabular}

According to the above equations, it is interesting to see the decrease in coefficient ' $a$ ' $\left(Y=a e^{b x}\right)$ values at each Series as the curing period increases. For example for $\mathrm{W} / \mathrm{C}=0.6$ at 1 day of curing the coefficient ' $\mathrm{a}$ ' is 13.968 and at 7 , 28 and 360 days' age this coefficient is $10.862,9.1052$ and 1.7877 which decreases with an increase in the curing period. 

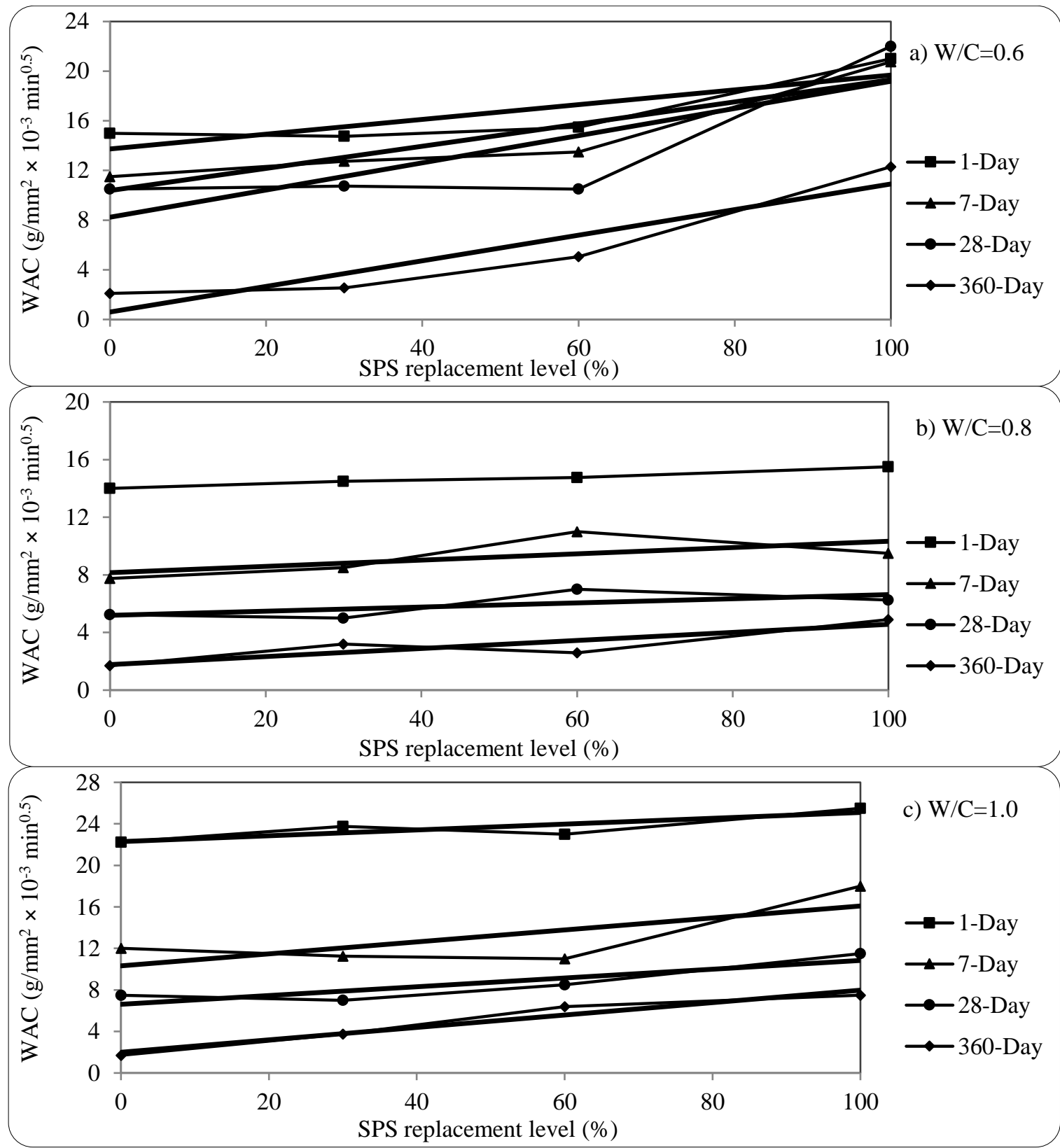

Figure 14. WAC of concrete containing varying amounts of SPS aggregate at different curing periods for W/C of $0.6,0.8$ and 1.0

The relationship between compressive strength and WAC of concrete containing varying amounts of SPS aggregate for all 3 series $(\mathrm{W} / \mathrm{C}=0.6,0.8$ and 1.0) and ages is shown in Figure 15. An exponential function seems to better describe the correlation between strength and WAC for SPS mixtures in all series where, $\mathrm{Y}$ is the compressive strength (MPa) and $\mathrm{X}$ is the WAC $\left(\mathrm{g} / \mathrm{mm}^{2} \times 10^{-3} \mathrm{~min}^{0.5}\right)$.

$$
\begin{aligned}
& Y=30.249 e^{-0.107 X}, \quad \mathrm{R}^{2}=0.76 \quad(\mathrm{~W} / \mathrm{C}=0.6) \\
& Y=19.681 e^{-0.162 X}, \quad \mathrm{R}^{2}=0.84 \quad(\mathrm{~W} / \mathrm{C}=0.8) \\
& Y=14.258 e^{-0.115 X}, \quad R^{2}=0.92 \quad(\mathrm{~W} / \mathrm{C}=1.0)
\end{aligned}
$$

The values $\left(\mathrm{R}^{2}=0.76,0.84\right.$ and 0.92$)$ represent a good correlation between the two compared parameters of strength and $\mathrm{WAC}$ in series $1(\mathrm{~W} / \mathrm{C}=0.6), 2(\mathrm{~W} / \mathrm{C}=0.8)$ and $3(\mathrm{~W} / \mathrm{C}=1.0$, respectively. It is interesting to see that the correlation between compared parameters became stronger with an increase in W/C ratio. It can be observed that the WAC increases with a decrease in compressive strength and it also increase with an increase of SPS aggregate content in the concrete mixes. 

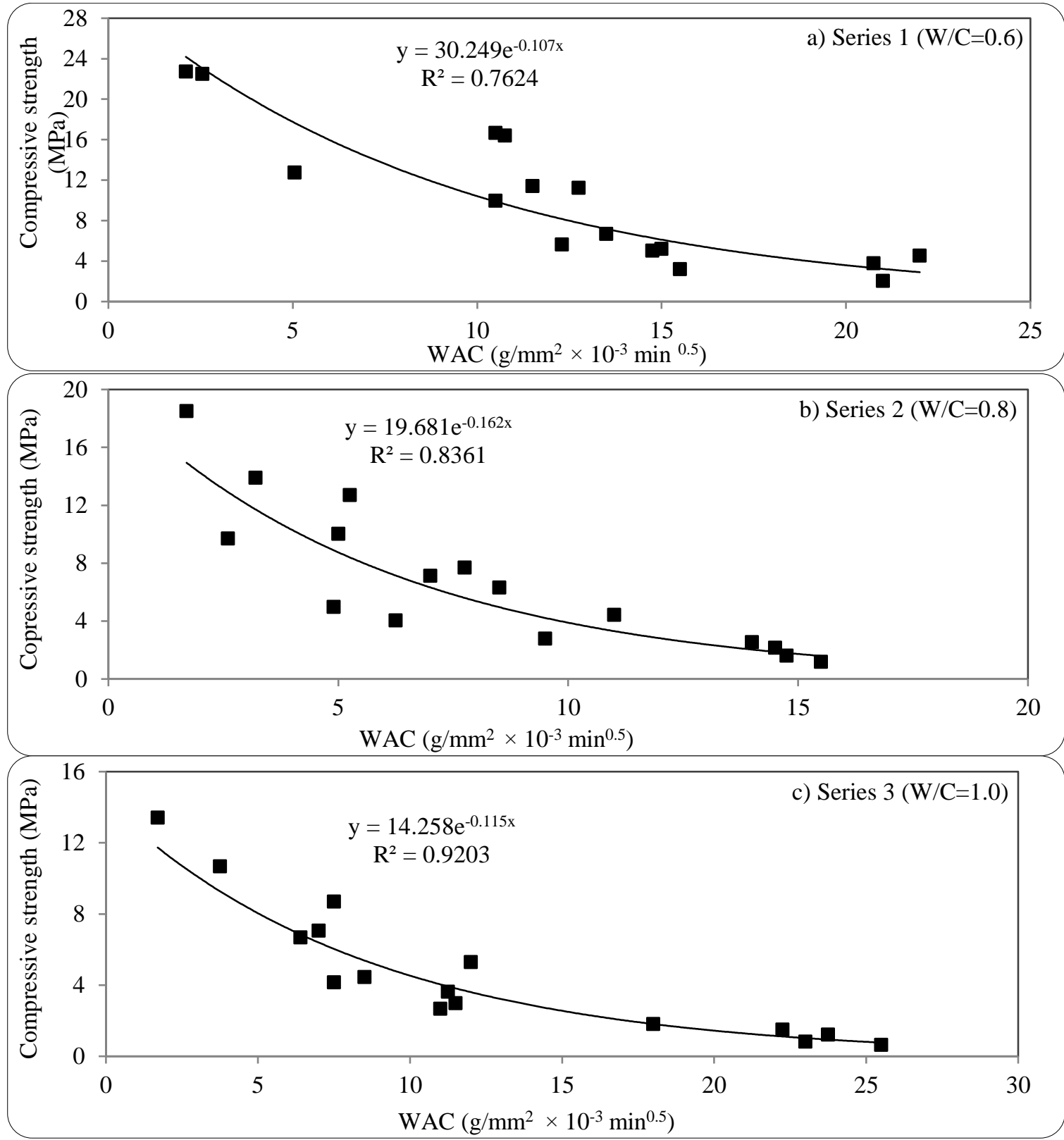

Figure 15. Correlation between strength and WAC of concrete containing varying amounts of $\mathrm{SPS}$ for $\mathrm{W} / \mathrm{C}=0.6, \mathrm{~W} / \mathrm{C}=\mathbf{0 . 8}$ and $\mathrm{W} / \mathrm{C}=\mathbf{1 . 0}$

\section{Conclusions}

The capillary water absorption, as indicated by rate of water absorbed per unit area, increases when natural aggregate is replaced with increasing amounts of SPS aggregates; thus, coating the surface of LWAC with water proofing material is recommended which may prevent the CWA. The increase in CWA is accompanied by a decrease in compressive strength. The level of decrease depends upon the replacement level of SPS. However, adequate strength can be achieved by using an appropriate replacement level of SPS. The concrete containing SPS can be used in low-strength concretes applications and to produce lightweight bricks and blocks with low thermal conductivity. If SPS aggregate is manufactured correctly, with appropriate concrete mix design, the utilisation of this novel lightweight aggregate made from waste EPS in lightweight concrete production is possible. However, more mechanical and durability experiments needed to be done before the materials could be proven $\mathrm{OK}$ for use in civil engineering applications.

\section{Acknowledgements}

The assistance from Soran University (Kurdistan-Iraq), Parry \& Associates Ltd. (U.K.) and University of Wolverhampton civil engineering's laboratory (U.K.) is gratefully acknowledged.

\section{References}

[1] Mehta, P.K. The next revolution in materials of construction, Proc. VII AIMAT congress, Ancona, Italy, 29 June - 2 July 2004 , 
Keynote Paper 1. (2004).

[2] Khatib, J. M., B. A. Herki, and S. Kenai. "Capillarity of concrete incorporating waste foundry sand." Construction and building materials 47 (2013): 867-871.

[3] Khatib, Jamal M., and Roger M. Clay. "Absorption characteristics of metakaolin concrete." Cement and Concrete Research 34 , no. 1 (2004): 19-29.

[4] Babu, Daneti Saradhi, K. Ganesh Babu, and Wee Tiong-Huan. "Effect of polystyrene aggregate size on strength and moisture migration characteristics of lightweight concrete." Cement and Concrete Composites 28, no. 6 (2006): 520-527.

[5] Chen, Bing, and Juanyu Liu. "Mechanical properties of polymer-modified concretes containing expanded polystyrene beads." Construction and Building Materials 21, no. 1 (2007): 7-11.

[6] Le Roy, Robert, Edouard Parant, and Claude Boulay. "Taking into account the inclusions' size in lightweight concrete compressive strength prediction." Cement and concrete research 35, no. 4 (2005): 770-775.

[7] Ismail, Idawati, Abdul Aziz Saim, and Abd. Latif Saleh. Properties of hardened concrete bricks containing expanded polystyrene beads. Universiti Teknologi Malaysia, 2003.

[8] Miled, K., K. Sab, and R. Le Roy. "Particle size effect on EPS lightweight concrete compressive strength: experimental investigation and modelling." Mechanics of Materials 39, no. 3 (2007): 222-240.

[9] Xu, Yi, Linhua Jiang, Jinxia Xu, Hongqiang Chu, and Yang Li. "Prediction of compressive strength and elastic modulus of expanded polystyrene lightweight concrete." Magazine of Concrete Research 67, no. 17 (2015): 954-962.

[10] Sayadi, Ali A., Juan V. Tapia, Thomas R. Neitzert, and G. Charles Clifton. "Effects of expanded polystyrene (EPS) particles on fire resistance, thermal conductivity and compressive strength of foamed concrete." Construction and Building Materials 112 (2016): 716-724.

[11] Ferrándiz-Mas, Verónica, Thomas Bond, E. García-Alcocel, and Chris R. Cheeseman. "Lightweight mortars containing expanded polystyrene and paper sludge ash." Construction and Building Materials 61 (2014): 285-292.

[12] Lo Monte, Francesco, Patrick Bamonte, and Pietro G. Gambarova. "Physical and mechanical properties of heat - damaged structural concrete containing expanded polystyrene syntherized particles." Fire and Materials 39, no. 1 (2015): 58-71.

[13] Ranjbar, Malek Mohammad, and S. Yasin Mousavi. "Strength and durability assessment of self-compacted lightweight concrete containing expanded polystyrene." Materials and Structures 48, no. 4 (2015): 1001-1011.

[14] Herki, B. A., and Jamal M. Khatib. "Valorisation of waste expanded polystyrene in concrete using a novel recycling technique." European Journal of Environmental and Civil Engineering (2016): 1-19.

[15] British Standards Institution-UK, BS EN 933-1. Tests for geometrical properties of aggregates. Part 1: Determination of particle size distribution - Sieving method. (2012).

[16] British Standards Institution, BS EN 12350-2., Testing fresh concrete. Part 2: Slump-test. (2009).

[17] British Standards Institution, BS EN 12350-5., Testing fresh concrete. Part 5: Flow table-test. (2009).

[18] British Standards Institution-UK, BS EN 12390-7. Testing hardened concrete Part 7: Density of hardened concrete. (2009).

[19] British Standards Institution-UK, BS EN 12390-3. Testing hardened concrete Part 3: Compressive strength of test specimens. (2009).

[20] British Standards Institution-UK, BS EN 12390-4. Testing hardened concrete Part 4: Compressive strength, Specification for testing machines. (2000).

[21] Khatib, J. M., and P. S. Mangat. "Absorption characteristics of concrete as a function of location relative to casting position." Cement and concrete research 25, no. 5 (1995): 999-1010.

[22] Kan, A. and Demirboğa, R. "Effect of cement and EPS beads ratios on compressive strength and density of lightweight concrete", Indian Journal of Engineering \& Materials Sciences, 14(April), (2007): 158-162.

[23] Ferrándiz-Mas, Verónica, and E. García-Alcocel. "Durability of expanded polystyrene mortars." Construction and Building Materials 46 (2013): 175-182.

[24] Sabaa, Ben, and Rasiah Sri Ravindrarajah. "Workability assessment for polystyrene aggregate concrete." In VII Quality Control Congress, pp. 18-21. 1999.

[25] Tang, W. C., Y. Lo, and A. B. I. D. Nadeem. "Mechanical and drying shrinkage properties of structural-graded polystyrene aggregate concrete." Cement and Concrete Composites 30, no. 5 (2008): 403-409.

[26] Hassanpour, Mahmoud, Payam Shafigh, and Hilmi Bin Mahmud. "Lightweight aggregate concrete fiber reinforcement-a review." Construction and Building Materials 37 (2012): 452-461.

[27] Hossain, Khandaker M. Anwar. "Properties of volcanic pumice based cement and lightweight concrete." Cement and concrete research 34, no. 2 (2004): 283-291.

[28] Demirboga, Ramazan, and Abdulkadir Kan. "Thermal conductivity and shrinkage properties of modified waste polystyrene aggregate concretes." Construction and Building Materials 35 (2012): 730-734.

[29] Kim, H. K., J. H. Jeon, and H. K. Lee. "Workability, and mechanical, acoustic and thermal properties of lightweight aggregate concrete with a high volume of entrained air." Construction and Building Materials 29 (2012): 193-200. 
[30] British Standards Institution, BS EN 206-1, Concrete Part 1: Specification, Performance, Production and Conformity. 2000.

[31] Fraj, Amor Ben, Mohamed Kismi, and Pierre Mounanga. "Valorization of coarse rigid polyurethane foam waste in lightweight aggregate concrete." Construction and Building Materials 24, no. 6 (2010): 1069-1077.

[32] Albano, C., N. Camacho, M. Hernandez, A. Matheus, and A. Gutierrez. "Influence of content and particle size of waste pet bottles on concrete behavior at different w/c ratios." Waste Management 29, no. 10 (2009): 2707-2716.

[33] CEB-FIP. Diagnosis and assessment of concrete structures - State of the art report, CEB Bulletin. (1989).

[34] Ünal, Osman, Tayfun Uygunoğlu, and Ahmet Yildiz. "Investigation of properties of low-strength lightweight concrete for thermal insulation." Building and Environment 42, no. 2 (2007): 584-590.

[35] Sengul, Ozkan, Senem Azizi, Filiz Karaosmanoglu, and Mehmet Ali Tasdemir. "Effect of expanded perlite on the mechanical properties and thermal conductivity of lightweight concrete." Energy and Buildings 43, no. 2 (2011): 671-676.

[36] Babu, K. Ganesh, and D. Saradhi Babu. "Performance of fly ash concretes containing lightweight EPS aggregates." Cement and concrete composites 26, no. 6 (2004): 605-611.

[37] Neville, A. M., Properties of Concrete, fourth edition, Pearson educated limited, Essex, UK. (2008).

[38] Choi, Yun-Wang, Dae-Joong Moon, Jee-Seung Chung, and Sun-Kyu Cho. "Effects of waste PET bottles aggregate on the properties of concrete." Cement and concrete research 35, no. 4 (2005): 776-781. 